\title{
Relationship between global indices of reactivity, electrodonating and electroaccepting powers, and the hammet constant in isatoic anhydride derivatives
}

\author{
J S DURAND-NICONOFF ${ }^{\mathrm{a}}$, L CRUZ-KURI ${ }^{\mathrm{a}}$, M H MATUS ${ }^{\mathrm{b}}$, J CORREA-BASURTO ${ }^{\mathrm{c}}$, \\ J S CRUZ-SÁNCHEZ ${ }^{a}$ and F R RAMOS-MORALES ${ }^{\mathrm{b}, *}$ \\ anstituto de Ciencias Básicas, Universidad Veracruzana, Xalapa, Veracruz, México \\ ${ }^{\mathrm{b}}$ Unidad de Servicios de Apoyo en Resolución Analítica, Universidad Veracruzana, Calle Luis Castelazo \\ Ayala S/N, Col. Industrial Animas, C.P. 91190, Xalapa, Veracruz, México \\ ${ }^{\mathrm{c}}$ SEPI (Laboratorio de Modelado Molecular), Escuela Superior de Medicina IPN, 11340, Mexico City, México \\ e-mail: framos@uv.mx
}

MS received 6 October 2009; revised 29 May 2010; accepted 13 June 2011

\begin{abstract}
The possible correlation between Hammett's constant $\left(\sigma_{\mathrm{p}}\right)$, a characteristic parameter of functional groups with electrodonating or electroaccepting properties, and two indices of global reactivity were calculated in the gas phase. Parameters associated to a set of 22 structural variants of isatoic anhydride $(2 \mathrm{H}-3$, 1-benzoxazin-2,4(1H)-dione, ISA), replaced with diverse functional groups, were explored applying linear and quadratic statistical models for numerical analysis of the results.
\end{abstract}

Keywords. Isatoic anhydride (ISA); global reactivity; Hammett constant

\section{Introduction}

Quantitative structure-activity relationship (QSAR) models have had an impressive development, thanks to the historically fundamental contributions of CrumBrown, ${ }^{1}$ Hammett, ${ }^{2}$ and Hansch, ${ }^{3}$ among others. The models have been successfully applied to biochemical systems, including interactions based on electronic, steric, and hydrophobic parameters with a systematic selection of the functional groups present in the molecule under study. The exponential growth of QSAR and the QSPRs shows that it is necessary to have a greater number of empirical descriptors, as well as theoretical and experimental ones, that reflect the molecular properties and explain physical, chemical and biochemical phenomena. The models are especially useful as predictors in areas like chemical or biological response, drug modelling, and toxicity studies. ${ }^{4}$

Based on these successes, one of the main objectives of organic physical chemistry is to determine how the electronic properties of a functional group effects the reactivity of a molecule. ${ }^{5,6}$ Studies of these effects, using established empirical relationships between parameters that are determined experimentally

*For correspondence and those that are calculated with computational methods, such as Density Functional Theory (DFT), ${ }^{7}$ have shown utility in various reports. ${ }^{8-10}$ Part of the success of this approach is due to the fact that DFT provides a solid framework to study chemical reactivity, ${ }^{7,8}$ calculated by simple equations that describe global and local indices of reactivity.

The behaviour of the reactivity, based on how these indices change, can explain whether the response of the system is due to withdrawing or donation charge. This distinction is of fundamental importance from the physical chemist's point of view. Recent reports ${ }^{11}$ demonstrate an interest in characterizing the reactivity with a molecular function related to an explicit response, such as a charge transfer process. Gázquez et al. ${ }^{12}$ have proposed a set of global reactivity descriptors. Thus, Gázquez et al. ${ }^{12}$, tried to define the indices of global and local reactivity using a model charge transfer mechanism. The proposed model may involve non-integer electron transfer between the molecular system and its surroundings. Here, the surroundings are modelled as an idealized free-electron bath, with zero chemical potential at $0 \mathrm{~K}$.

The proposed model is based on a Taylor Series expansion of the energy, $E$, as a function of the number of electrons, $N$, keeping terms up to second order. Given the discrete character of the energy function in 
terms of the number of electrons, Gázquez et al. ${ }^{12}$, proposed a second degree interpolating function with different parameters for each of the intervals (one spanned between $N-1$ and $N$ and the other one between $N$ and $N+1$ ). The first interval corresponds to a process of electronic charge donation to the molecular system, whereas the second one corresponds to the attraction of an electronic charge. In both cases, the expansion is done around $N$, the number of electrons in the reference state. The characteristics of each curve are such that the difference in the first lateral derivatives of the energy with respect to the number of electrons (with a constant external potential) is equal to the common curvature of both parabolas in $N$. These first derivatives are, by definition, the chemical potentials $\mu^{-}$and $\mu^{+}$, which drive the processes of charge donation and attraction, respectively. ${ }^{13-16}$ The common curvature is equal to the second partial derivative of the energy with respect to the number of electrons. This derivative is, by definition, the chemical hardness $\eta \cdot{ }^{17}$ These adjustments correspond to the fact that the direction of charge flow is fundamentally driven by the chemical potential.

Therefore, following Gázquez et al. the electrodonating power, $\omega^{-}$, and the electroaccepting power, $\omega^{+}$, are defined in terms of the square of the chemical potential, $\left(\mu^{ \pm}\right)^{2}$, and by the common hardness, $\eta$, associated with both processes. This fact satisfies the relationship:

$$
\omega^{\mp}=\frac{\left(\mu^{\mp}\right)^{2}}{2 \eta},
$$

which describes the propensity of the system to donate or accept a charge in fractional quantities without saturation. This propensity is simultaneously determined by the square of the respective chemical potential as well as by the resistance (described by $\eta$ ) to the exchange of electronic charge with the surrounding environment. In a similar manner, these authors show that the chargeaccepting process stabilizes the system in a way that the larger values of $\omega^{+}$entail a greater power for electron acceptance, whereas the charge-donation process destabilizes the system, meaning that smaller values of $\omega^{-}$ imply a greater electron donating ability.

Under this approach, our work has the goal of determining the possible relationship between Hammett's constant $\left(\sigma_{\mathrm{p}}\right)$ and a linear combination of the indices (as calculated in gas phase) of the electroaccepting, $\omega^{+}$, and the electrodonating, $\omega^{-}$, power ${ }^{12}$ of isatoic anhydride (2H-3,1-benzoxazin-2,4(1H)-dione, ISA, see figure 1). ${ }^{19-22}$ We also study the monosubstituted compound with 22 different functional groups. This analysis will allow us to test Hammett's constant $\left(\sigma_{\mathrm{p}}\right)$, as reported by Hansch et al. ${ }^{18}$ who found that a positive

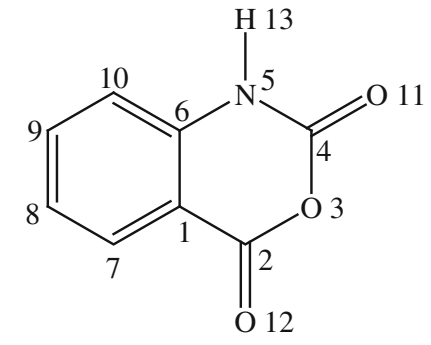

Figure 1. Chemical structure of ISA.

value of $\sigma_{\mathrm{p}}$ is associated with an electron accepting substituting group, while a negative value is associated with an electron donating substituting group. With the obtained model, ${ }^{23}$ we also explore the electronic contribution intrinsic to Hammett's constant for this molecular system. The different substituent groups were applied to the ISA system in a similar way to the one used in the substituted ethylene study carried out by Domingo et al. ${ }^{10}$

\section{Theoretical model}

The practical calculations of the global indices of reactivity (such as $\omega^{+}$and $\omega^{-}$), under the approximations of Gázquez, were performed by substituting the approximating terms in finite differences of the derivatives involved in the definitions of $\mu_{ \pm}$and $\eta$ in equation (1). This expressed in terms of the vertical ionization potential, $I$, and the electron affinity, $A$. The formulae are written in terms of the electronic energy, $E$, as follows:

$$
\begin{gathered}
I=E[N-1, V(r)]-E[N, V(r)], \\
A=E[N, V(r)]-E[N+1, V(r)],
\end{gathered}
$$

where $N$ refers to the number of electrons of the neutral molecule, $N+1$ to the anion, and $N-1$ to the cation. $V(r)$ indicates that the external potential remains constant. Gázquez et al. propose the following expressions for $\omega^{+}$ and $\omega^{-}$:

$$
\begin{aligned}
& \omega^{-}=\frac{(3 I+A)^{2}}{16(I-A)}, \\
& \omega^{+}=\frac{(I+3 A)^{2}}{16(I-A)} .
\end{aligned}
$$

These equations show that, up to this approximation, the electrodonating power is a reactivity index that assigns a greater weight to $I$ in comparison to that of the electron affinity, $A$. In contrast, the electroaccepting power exhibits the opposite behaviour, assigning a greater weight to $A$ than to $I$. Finally, the electrofilicity 
index assigns equal weights to both, $I$ and $A,{ }^{24}$ without distinguishing between the charge-donating and charge-accepting processes. This index quantifies only the stabilization in energy when the system acquires the maximum amount of electronic charge from its surroundings.

Gázquez et al. also consider a study of local properties that characterize the charge-donating and chargeaccepting processes. This study leads us to the task of finding possible correlations among these indices and the Hammett's constant, all of which may be very relevant; however, this task will be deferred to a later work.

\section{Computational details}

The geometry of ISA was fully optimized from the atomic positions determined by X-ray diffraction. ${ }^{25}$ The level of calculation employed consists of the hybrid functional, B3LYP, and the Dunning's augmented and correlated basis set, aug-cc-pVDZ. This level of calculation produced comparable results to those in an experimental study of ISA performed in a previous work. ${ }^{26}$ Calculation of the frequencies, at the same level, showed that the geometry corresponds to a local energy minimum. Each functional group was substituted on the optimized geometry, and the structure obtained was completely re-optimized, including frequency calculations.

In every case, $I$ and $A$ were obtained using equations (2) and (3). To accomplish this, single point calculations were performed for the cationic and anionic systems. These systems were based on the optimized geometry of the respective neutral molecule, thus assuring that $V(r)$ is constant in every case. For the ionic systems, the UB3LYP/aug-cc-pVDZ level of calculation was used, and the results showed no spin contamination. All calculations were performed using the computational package Gaussian 03. ${ }^{27}$ The calculated values for $I$ and $A$ were substituted in equations (4) and (5) to obtain $\omega^{+}$and $\omega^{-}$, respectively.

\section{Statistical details}

The calculated values we obtained for $\omega^{-}$and $\omega^{+}$have shown frequency distributions that approximately follow the Gaussian model. The normality assumption is accepted to validate the statistical inferences about regression and correlation parameters. Under the normality assumption and for the calculation of the determination coefficient $\left(\mathrm{R}^{2}\right),{ }^{23}$ one must keep in mind that the obtained values are point estimations and that a more conservative analysis should include interval estimates. Thus, for instance, a point estimation of $\mathrm{R}^{2}$ equal to $0.90^{2}$ based on a sample of size $n=22$ (as it actually corresponds to our experimental data) yields a $95 \%$ confidence interval that ranges from 0.5944 to 0.9178 (see section 5). Doubling our sample size would not substantially increase the lower limit (which corresponds to the worst scenario) as it can be calculated. ${ }^{23}$ Note that the confidence interval of $\mathrm{R}$ is symmetrical around the observed value only with large values of $n$.

\section{Results and discussion}

A calculation of the strength of association between $\omega^{-}$ and $\omega^{+}$shows that these variables have a high squared correlation, $\mathrm{R}^{2}=0.956$, for a linear model and even higher, $\mathrm{R}^{2}=0.966$, for a quadratic model.

The following multiple linear regression model seems a natural first choice to get a good fit for $\sigma_{\mathrm{p}}$ :

$$
\sigma_{\mathrm{p}}^{\mathrm{fit}}=\mathrm{b}_{0}+\mathrm{b}_{1} \omega^{-}+\mathrm{b}_{2} \omega^{+},
$$

where $\omega^{-}$and $\omega^{+}$are the independent variables. This model gives rise to the corresponding point estimations for the regression coefficients and their respective significance probabilities. It turns out that the regression coefficient for the $\omega^{-}$variable is not significantly distinct from zero (significance probability $=0.685$ ); because of this result, even when $\mathrm{R}^{2}=0.870$, one can omit the $\omega^{+}$variable. This decision is also supported by the fact that $\omega^{-}$and $\omega^{+}$are almost linearly dependent as functions and the multicollinearity statistics are significant. Therefore, we shall consider the following reduced model:

$$
\sigma_{\mathrm{p}}^{\mathrm{fit}}=\mathrm{b}_{0}+\mathrm{b}_{1} \omega^{-}+\mathrm{b}_{2}\left(\omega^{-}\right)^{2} .
$$

It is apparent from figure 2 that the fitting carried out through the quadratic model (Eq. 7) is better than the corresponding one for the linear model (Eq. 6). This conclusion is also corroborated when the corresponding determination coefficients are calculated: $\mathrm{R}^{2}=0.869$ for the linear model vs. $\mathrm{R}^{2}=0.903$ for the quadratic model (see table 1).

Additionally, the 'leave out one observation, cross validation' procedure was used. As described by Allen, ${ }^{28}$ we obtained the sum of squares of the discrepancies for the given model by leaving out one observation, fitting the given model to the rest of the data, and then predicting the one left out, thus obtaining the square of the discrepancy and, finally, repeating this for 


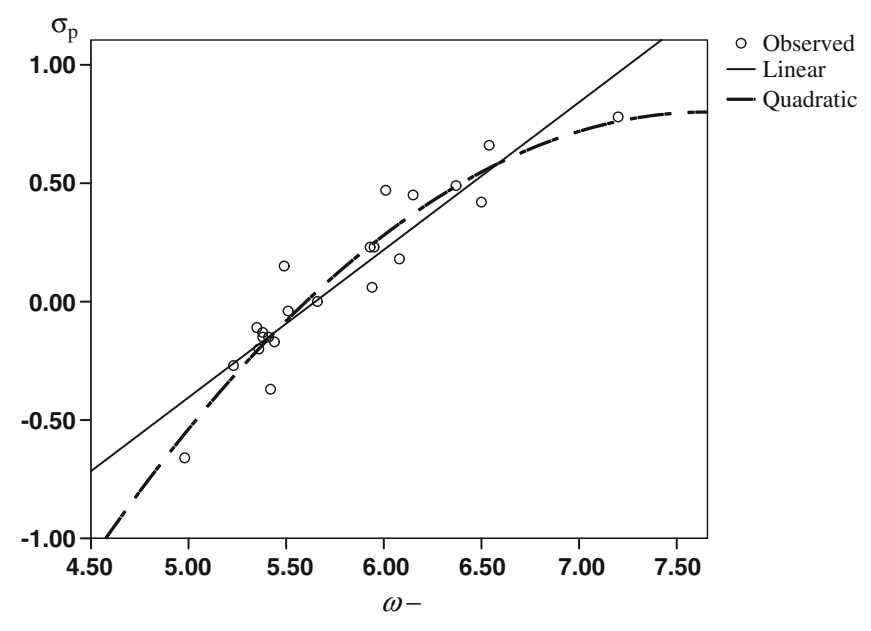

Figure 2. Curvilinear regression between $\omega^{-}$and $\sigma_{\mathrm{p}}$.

all single data point omissions. This process was followed for several competing models, as discussed in the Appendix I. The results of this cross validation are summarized in table 2. Model 1 is the same one as equation (7), and it is cross validated in this fashion because $\sum\left(\sigma_{\mathrm{p}}^{\text {fit }}-\sigma_{\mathrm{p}}\right)^{2}=0.34$ corresponds to the smallest value among all of these models. Thus, with the quadratic model, one gets an increase of 0.034 in the explaining fraction of the $\omega^{-}$variable ( $\mathrm{R}^{2}$ difference). The regression coefficients for the quadratic model are presented in table 1.

We present the results of our calculations in table 3; the quantities that appear in the third column of table 3 were calculated using model (7). As table 3 shows, the calculated values for the electron-donating and the electron-accepting powers are, in general, similar to the ones given by Hammett's constant. For the compound under consideration, unsubstituted ISA $(\mathrm{X}=\mathrm{H})$, the Hammett's constant equals zero. For compounds with electron-donating functional groups, $\sigma_{\mathrm{p}}$ systematically decreases through negative values from zero to -0.66 when the substituent is $\mathrm{NH}_{2}$, the most electron-donating one of the series. In a consistent manner, the values calculated for $\omega^{-}$decrease from $5.66 \mathrm{eV}$ (when $\mathrm{X}=\mathrm{H}$ ) to $4.98 \mathrm{eV}$ (the value associated with the $\mathrm{NH}_{2}$ substituent). For $\omega^{-}$values, the decreasing tendency is not strictly uniform; for instance, compounds with the $\mathrm{CH}_{3}\left(\mathrm{CH}_{2}\right)_{2}$, $\left(\mathrm{CH}_{3}\right)_{2} \mathrm{CH}-, \mathrm{CH}_{3} \mathrm{CH}_{2^{-}}, \mathrm{CH}_{3^{-}}$, and $(\mathrm{CH})_{3} \mathrm{C}$ - substituent groups have an electron-donating capacity less than that for ISA without a substituent but greater than that for $\mathrm{NH}_{2} \mathrm{CH}_{2}-$. We emphasize that a smaller $\omega^{-}$value corresponds to a greater electron-donating capacity. Likewise, $\omega^{-}$values associated with positive $\sigma_{\mathrm{p}}$ increase from $5.66 \mathrm{eV}$ (when $\mathrm{X}=\mathrm{H}$ ) to $7.20 \mathrm{eV}$ (corresponding to the $\mathrm{NO}_{2}$ substituent). This trend indicates decreasing electron-donating capacity.

Pertaining to the electroaccepting capacity, $\omega^{+}$ decreases from $0.85 \mathrm{eV}$ to $0.74 \mathrm{eV}$, representing weaker electroaccepting capacity, stressing the $0.94 \mathrm{eV}$ value for the compound with substituent $\mathrm{CH} 2=\mathrm{CH}-$, the largest value in this range, and lying above the associated ISA value without a substituent. On the other side of the scale, toward the electron-attracting substituents, the tendencies of $\omega^{+}$and $\omega^{-}$are consistent with the ones shown by the values of $\sigma_{\mathrm{p}}: \omega^{-}$increases from $5.6 \mathrm{eV}$ to $7.20 \mathrm{eV}$ for $\mathrm{NO} 2$ (the most electronattracting compound), and $\omega^{+}$increases from $0.85 \mathrm{eV}$ to $1.60 \mathrm{eV}$, again showing increasing electroaccepting capacity. Just as in the negative part of $\sigma_{p}$, the positive indices do not have a uniform increment with respect to $\sigma_{p}$. Perhaps this behaviour is due to the solvent effect present in $\sigma_{\mathrm{p}}$ and also to the fact that it is not considered in these gas phase calculations. Another possible factor for this discrepancy, although to a lesser extent, may be the basis set used, which might not be sufficient in some cases to describe with accuracy of the substituent effect of the compound, especially those in the second and third rows of the periodic table.

Table 1. Regression coefficients of two models (linear and quadratic) to fit $\sigma_{\mathrm{p}}$ using $\omega^{-}$as the independent variable.

\begin{tabular}{lcccccccc}
\hline \multirow{8}{*}{ Model } & \multicolumn{7}{c}{ Model summary and parameter estimation } \\
\cline { 2 - 9 } & $\mathrm{R}^{2}$ & $\mathrm{~F}^{\mathrm{a}}$ & $\mathrm{df1}^{\mathrm{b}}$ & $\mathrm{df}^{\mathrm{c}}$ & Significance & $\mathrm{B}_{0}$ & $\mathrm{~b}_{1}$ & $\mathrm{~b}_{2}$ \\
\hline Linear $^{\mathrm{d}}$ & 0.869 & 132.814 & 1 & 20 & 0.000 & -3.521 & 0.623 & \\
Quadratic $^{\mathrm{e}}$ & 0.903 & 88.884 & 2 & 19 & 0.000 & -10.326 & 2.907 & -0.190 \\
\hline
\end{tabular}

${ }^{\mathrm{a}} \mathrm{F}$ is the Fisher's test statistic. ${ }^{\mathrm{b}} \mathrm{df} 1$ is the number of degrees of freedom in the numerator for the Fisher's distribution corresponding to the model. ${ }^{\mathrm{c}} \mathrm{df} 2$ is the number of degrees of freedom in the denominator for the Fisher's distribution corresponding to the model. ${ }^{\mathrm{d}}$ Equation (6). ${ }^{\mathrm{e}}$ Equation (7) 
Table 2. Descriptive statistics for squares of discrepancies in six models.

\begin{tabular}{lccccc}
\hline $\begin{array}{l}\text { Squared } \\
\text { discrepancy } \\
\text { for model }\end{array}$ & $N$ & Minimum & Maximum & Sum & Mean \\
\hline Model 1 & 22 & .00 & .07 & .34 & .0153 \\
Model 2 & 22 & .00 & .11 & .51 & .0232 \\
Model 3 & 22 & .00 & .07 & .42 & .0193 \\
Model 4 & 22 & .00 & .26 & .75 & .0339 \\
Model 5 & 22 & .00 & .15 & .96 & .0435 \\
Model 6 & 22 & .00 & & & .0241 \\
\hline Valid $N$ & 22 & & &
\end{tabular}

Table 3. $\sigma_{\mathrm{p}}, \sigma_{\mathrm{p}}^{\mathrm{fit}}$ and calculated electrodonating and electroaccepting powers, $\omega^{-}, \omega^{+}$, as well as $I$ and $A$ for ISA with different substituents, X, on the aromatic ring.

\begin{tabular}{|c|c|c|c|c|c|c|}
\hline$X$ & $\sigma_{\mathrm{p}}$ & $\sigma_{\mathrm{p}}^{\mathrm{fit}}\left(\omega^{-}\right)$ & $\omega^{-}(\mathrm{eV})$ & $\omega^{+}(\mathrm{eV})$ & $I(e V)$ & $A(e V)$ \\
\hline $\mathrm{NH}_{2}$ & -0.66 & -0.56 & 4.98 & 0.74 & 8.00 & 0.48 \\
\hline $\mathrm{OH}$ & -0.37 & -0.15 & 5.42 & 0.86 & 8.51 & 0.63 \\
\hline $\mathrm{CH}_{3} \mathrm{O}-$ & -0.27 & -0.32 & 5.23 & 0.80 & 8.29 & 0.56 \\
\hline$(\mathrm{CH})_{3} \mathrm{C}-$ & -0.20 & -0.20 & 5.36 & 0.72 & 8.57 & 0.53 \\
\hline $\mathrm{CH}_{3-}^{-}$ & -0.17 & -0.13 & 5.44 & 0.82 & 8.70 & 0.55 \\
\hline $\mathrm{CH}_{3} \mathrm{CH}_{2-}$ & -0.15 & -0.16 & 5.41 & 0.81 & 8.65 & 0.54 \\
\hline$\left(\mathrm{CH}_{3}\right)_{2} \mathrm{CH}-$ & -0.15 & -0.18 & 5.38 & 0.81 & 8.60 & 0.54 \\
\hline $\mathrm{CH}_{3}\left(\mathrm{CH}_{2}\right)_{2-}$ & -0.13 & -0.18 & 5.38 & 0.81 & 8.60 & 0.54 \\
\hline $\mathrm{NH}_{2} \mathrm{CH}_{2-}^{-}$ & -0.11 & -0.21 & 5.35 & 0.80 & 8.58 & 0.52 \\
\hline $\mathrm{CH}_{2}=\mathrm{CH}-$ & -0.04 & -0.08 & 5.51 & 0.94 & 8.36 & 0.77 \\
\hline $\mathrm{H}$ & 0 & 0.04 & 5.66 & 0.85 & 9.07 & 0.56 \\
\hline $\mathrm{F}$ & 0.06 & 0.24 & 5.94 & 1.01 & 9.05 & 0.82 \\
\hline $\mathrm{SH}$ & 0.15 & -0.09 & 5.49 & 0.94 & 8.33 & 0.77 \\
\hline $\mathrm{CNCH}_{2-}$ & 0.18 & 0.32 & 6.08 & 1.08 & 9.08 & 0.92 \\
\hline $\mathrm{Br}$ & 0.23 & 0.23 & 5.93 & 1.06 & 8.83 & 0.91 \\
\hline $\mathrm{Cl}$ & 0.23 & 0.24 & 5.95 & 1.04 & 8.92 & 0.89 \\
\hline $\mathrm{CHO}$ & 0.42 & 0.54 & 6.50 & 1.26 & 9.31 & 1.17 \\
\hline $\mathrm{CO}_{2} \mathrm{H}$ & 0.45 & 0.36 & 6.15 & 1.08 & 9.23 & 0.92 \\
\hline $\mathrm{COCH}\left(\mathrm{CH}_{3}\right)_{2}$ & 0.47 & 0.28 & 6.01 & 1.07 & 8.95 & 0.92 \\
\hline NC- & 0.49 & 0.48 & 6.37 & 1.22 & 9.19 & 1.12 \\
\hline $\mathrm{CN}$ & 0.66 & 0.56 & 6.54 & 1.27 & 9.36 & 1.18 \\
\hline $\mathrm{NO}_{2}$ & 0.78 & 0.75 & 7.20 & 1.60 & 9.64 & 1.57 \\
\hline
\end{tabular}

The regression analysis, as shown in the statistical results, exhibits a strong linear correlation between $\sigma_{p}$ and the square of the $\omega^{-}$values, according to the equation below:

$$
\sigma_{\mathrm{p}}^{\mathrm{fit}}\left(\omega^{-}\right)=-0.19\left(\omega^{-}\right)^{2}+2.91 \omega^{-}-10.33
$$

For this fitting model, the square of the correlation coefficient is such that $R^{2}=0.90$ and $\sigma_{p}^{\text {fit }}\left(\omega^{-}\right)$can be interpreted as the theoretical contribution to the experimental value of the Hammett's constant. According to this value of $R^{2}, 90 \%$ of the variation of $\sigma_{\mathrm{p}}$ is explained by the variation of $\omega^{-}$.
The calculated values of $\sigma_{p}^{\text {fit }}\left(\omega^{-}\right)$for all of the series of substituted ISA compounds are compared with the corresponding values for $\sigma_{\mathrm{p}}$ in the first two columns of table 1 . The scale determined by $\sigma_{\mathrm{p}}^{\mathrm{fit}}$ indicates that the ISA derivative with the most electron-donating substituent, $\mathrm{NH}_{2}$, corresponds to the negative value with the smallest value of $\sigma_{\mathrm{p}}^{\mathrm{fit}}$, which is -0.56 . Similarly, the ISA compound with the most electron-attracting substituent, $\mathrm{NO}_{2}$, is associated with the largest value of $\sigma_{\mathrm{p}}^{\mathrm{fit}}$, which is 0.75 . Therefore, our results are in good agreement with those of other authors using an analogous methodology. ${ }^{29,30}$ 
We emphasize the fact that the statistical analysis of the regression coefficient for $\omega^{+}$in the Eq. (6) is not significantly different from zero. For this reason, even though $\mathrm{R}^{2}=0.87$, one can omit $\omega^{+}$as a variable in our model. That is, the variability of $\sigma_{\mathrm{p}}$ can be explained in a reasonable way by $\omega^{-}$only.

\section{Conclusions}

The global indices $\omega^{+}$and $\omega^{-}$were calculated using DFT for a series of ISA derivatives. These quantities may be used to estimate the intrinsic electronic contributions related to Hammett's constant, $\sigma_{p}$, taking into account 22 functional groups that are usually present in organic molecules. In general, it was found that the electroattracting $\left(\omega^{+}\right)$and electrodonating capacity $\left(\omega^{-}\right)$both follow approximately the same trend as that of $\sigma_{\mathrm{p}}$. Additionally, the proposed scale using our model for $\sigma_{\mathrm{p}}^{\text {fit }}\left(\omega^{-}\right)$is consistent, at least with the most extreme values given for $\sigma_{\mathrm{p}}$. These calculations give us an idea about the ability of electrodonating and electroattracting capacity with respect to activation and deactivation of functional groups in these compounds. These results may be applied to studies using (QSAR) models. ${ }^{3,31,32}$

In addition, we found a good fit for this set of molecules. However, the model may or may not be transferable to other types of organic compounds, and further work about this issue is needed. We thus can conclude that this fit yields reliable results for ISA and its substituted derivatives, but evaluation of this and other models is required when working with different types of molecules.

We are aware that our results only show the global reactivity of this family of molecules. We are convinced of the need to continue this analysis by introducing local reactivity indices, since these will be helpful for detecting reactivity sites on each molecular system. We are currently working on exploring the relationship between the Hammettt constant and the local indices, $\omega^{+/-}$. We are also applying local indices that have shown adequate results to explain molecular reactivity, such as: (a) the relative electrophilicity $\left(s^{+} / s^{-}\right)$ and relative nucleophilicity $\left(s^{-} / s^{+}\right),{ }^{33}$ which help to predict preferable intramolecular reactive sites; and (b) the group softness $\left(s_{\mathrm{g}}\right),{ }^{34}$ which can be computed by adding the sum of the local softness of the reacting atom and the atoms in its neighbourhood (i.e., the atoms bonded to the reactive atom), this local index was found to effectively predict intermolecular reactive sequences. The results of these analyses will give an insight on the local reactivity for these molecular systems.

\section{Acknowledgement}

This work was supported by grants from PROMEP/ 103.5/08/1073 to FRRM, CONACYT-México 62488 to JCB and financial support through the Programa de Repatriación: MOD-ORD-70-08 PCI-1054-11-08 for MHM.

\section{Appendix I. Six final competing models}

$$
\begin{aligned}
& \text { Model 1: } \sigma_{\mathrm{p}}^{\mathrm{fit}}=\mathrm{b}_{0}+\mathrm{b}_{1} \omega^{-}+\mathrm{b}_{2}\left(\omega^{-}\right)^{2} \\
& \text { Model 2: } \sigma_{\mathrm{p}}^{\text {fit }}=\mathrm{b}_{0}+\mathrm{b}_{1} A+\mathrm{b}_{2} I \\
& \text { Model 3: } \sigma_{\mathrm{p}}^{\mathrm{fit}}=\mathrm{b}_{0}+\mathrm{b}_{1} A+\mathrm{b}_{2} A^{2}+\mathrm{b}_{3} I+\mathrm{b}_{4} I^{2} \\
& \text { Model 4: } \sigma_{\mathrm{p}}^{\mathrm{fit}}=\mathrm{b}_{0}+\mathrm{b}_{1} \omega^{-}+\mathrm{b}_{2} \omega^{+}+\mathrm{b}_{3} A+\mathrm{b}_{4} I \\
& \text { Model 5: } \sigma_{\mathrm{p}}^{\mathrm{fit}}=\mathrm{b}_{0}+\mathrm{b}_{1} I+\mathrm{b}_{2} I^{2} \\
& \text { Model 6: } \sigma_{\mathrm{p}}^{\mathrm{fit}}=\mathrm{b}_{0}+\mathrm{b}_{1} A+\mathrm{b}_{2} A^{2}
\end{aligned}
$$

Model 1 corresponds to the one shown in equation (7) in the text.

\section{References}

1. Brown A C and Gibson J 1892 Chem. Soc. Trans. 61367

2. Hammett L P 1935 Chem. Rev. 17125

3. Hansch C and Selassie C 2006 Comprehensive medicinal chemistry II, Pomona College, Claremont, CA, USA.: J B Taylor, D J Triggle (eds) Publisher Elsevier Ltd., 443

4. Chattaraj P K, Nath S and Maiti B 2003 Reactivity descriptors. In: Computational Medicinal Chemistry for Drug Discovery J Tollenaere, P Bultinck, H D Winter and W Langenaeker (eds) (New York: Marcel Dekker) 11295

5. Exner O 1972 Advances in linear free energy relationships. N B Chapman, J Shorter (eds): London, UK: Plenum

6. Gordillo B and Ramos-Morales F R 1997 Educación Química VIII 127

7. Parr R G and Yang W 1989 Density functional theory of atoms and molecules. New York: Oxford University Press

8. Pérez P, Simón-Manso Y, Aizman A, Fuentealba P and Contreras R 2000 J. Am. Chem. Soc. 1224756

9. Domingo L R, Pérez P and Contreras R 2003 J. Org. Chem. $\mathbf{6 8} 6060$

10. Domingo L R 2002 Tetrahedron 583785

11. Chattaraj P K, Sarkar U and Roy D R 2006 Chem. Rev. 1062065

12. Gázquez J L, Cedillo A and Vela A 2007 J. Phys. Chem. A111 1966

13. Jaffé H H 1953 Chem. Rev. 53191

14. March J 1998 Advanced organic chemistry: Reactions, mechanisms and structure. New York: Wiley and Sons

15. Gómez B, Likhanova N V, Domínguez-Aguilar N A, Martínez-Palou R, Vela A and Gázquez J L 2006 J. Phys. Chem. B110 8928 
16. Parr R G, Donnelly R A, Levy M and Palke W E 1978 J. Chem. Phys. 683801

17. Parr R G and Pearson R G 1983 J. Am. Chem. Soc. 105 7512

18. Hanch C, Leo A and Taft R W 1991 Chem. Rev. 91165

19. Sherwin Williams, Technical Bulletin No. 152. Available from Sherwin Williams Co.

20. Coppola G M 1980 Synthesis 7505

21. Shvekhgeimer M G A 2001 Chem. Heterocyc. Comp. 37 385

22. Weissleder R, Kelly K, Sun E, Shtatland T and Josephson L 2005 Nat Biotechnol 231418

23. Draper N R and Smith H 1998 Applied regression analysis, 3rd ed. John Wiley \& Sons

24. Parr R G, Von Szentpaly L and Liu S B 1999 J. Am. Chem. Soc. 1211922

25. Kashino S, Nakashima S and Haisa M 1978, Acta, Crystallogy. B34 2191

26. Ramos-Morales F R, Durand-Niconoff J S, CorreaBasurto J, Meléndez-Bustamante F J and Cruz-Sánchez J S 2008 J. Mex. Chem. Soc. 52241

27. Gaussian 03, Revision A.1, Frisch M J, Trucks G W, Schlegel H B, Scuseria G E, Robb M A, Cheeseman J R, Montgomery J A Jr, Vreven T, Kudin K N, Burant J C, Millam J M, Iyengar S S, Tomasi J, Barone V, Mennucci B, Cossi M, Scalmani G, Rega N, Petersson G A, Nakatsuji H, Hada M, Ehara M, Toyota K, Fukuda R, Hasegawa J, Ishida M, Nakajima T, Honda Y, Kitao O, Nakai H, Klene M, Li X, Knox J E, Hratchian H P, Cross J B, Adamo C, Jaramillo J, Gomperts R,
Stratmann R E, Yazyev O, Austin A J, Cammi R, Pomelli C, Ochterski J W, Ayala P Y, Morokuma K, Voth G A, Salvador P, Dannenberg J J, Zakrzewski V G, Dapprich S, Daniels A D, Strain M C, Farkas O, Malick D K, Rabuck D K, Raghavachari K, Foresman J B, Ortiz J V, Cui Q, Baboul A G, Clifford S, Cioslowski J, Stefanov B B, Liu G, Liashenko A, Piskorz P, Komaromi I, Martin R L, Fox D J, Keith T, Al-Laham M A, Peng C Y, Nanayakkara A, Challacombe M, Gill P M W, Johnson B, Chen W, Wong M W, Gonzalez C, and Pople J A, Gaussian, Inc., Pittsburgh PA, 2003

28. Allen, D M 1971 The prediction sum of squares as a criterion for selecting predictor variables. Technical Report No. 23, Department of Statistics, University of Kentucky

29. Meneses L, Araya A, Pilaquinga F and Fuentealba P 2008 Chem. Phys. Lett. 46027

30. Elango M, Parthasarathi R, Karthik Narayanan G, Sabeelullah A M D, Sarkar U, Venkatasubramaniyan N S, Subramanian V and Chattaraj P K 2008 J. Chem. Sci. 11761

31. Parthasarathi R, Subramanian V, Roy D R and Chattaraj P K 2004 Bioorg. Med. Chem. 125533

32. Parthasarathi R, Padmanabhan J, Subramanian V, Maiti B and Chattaraj P K 2003 J. Phys. Chem. A107 10346

33. Roy R K, Krishnamurty S, Geerlings P and Pal S 1988 J. Phys. Chem. A102 3746

34. Krishnamurty S, and Pal S, 2000 J. Phys. Chem. A104 7639 